Revista Universo Contábil, ISSN 1809-3337
Blumenau, v. 14, n. 1, p. 93-114, jan./mar., 2018
Disponível em www.furb.br/universocontabil

\title{
CULTURA ORGANIZACIONAL E PRÁTICAS DE CONTABILIDADE GERENCIAL NO AGRONEGÓCIO COOPERATIVO ${ }^{1}$
}

\section{ORGANIZATIONAL CULTURE AND MANAGEMENT ACCOUNTING PRACTICES IN THE CORPORATE AGRIBUSINESS}

\section{CULTURA ORGANIZACIONAL E PRÁCTICAS DE CONTABILIDAD GERENCIAL EN COOPERATIVAS AGROPECUARIAS}

\begin{abstract}
Marcelo Resquetti Tarifa
Pós-Doutor em Contabilidade pela Universidade Federal do Paraná Doutor em Desenvolvimento Regional e Agronegócio pela Universidade Estadual do Oeste do Paraná Professor do Departamento de Ciências Contábeis da Universidade Estadual de Londrina Endereço: Rod. Celdo Garcia Cid (PR-445) Km 380 - Campus Universitário CEP: 86057-970 - Londrina - PR - Brasil E-mail: marcelotarifa@hotmail.com Telefone: (43) 3371-4265

Lauro Brito de Almeida Pós-Doutor em Controladoria e Contabilidade pela Universidade de São Paulo Doutor em Contabilidade pela Universidade de São Paulo Professor Aposentado do PPG em Contabilidade da Universidade Federal do Paraná Educação em Gestão Econômica de Negócios Endereço: Av. Visconde de Guarapuava, 4517, ap. 171 CEP: 80240-010 - Curitiba - PR - Brasil E-mail: gbrito@uol.com.br Telefone: (41) 3360-4404
\end{abstract}

\section{RESUMO}

Apesar da recessão econômica que assolou o Brasil a partir do ano de 2015, resultando em um Produto Interno Bruto negativo de 3,8\%, as cooperativas agropecuárias do Estado do Paraná obtiveram um crescimento de $20 \%$ no valor de suas receitas de vendas, além de sobras representativas (OCB, 2016). No mesmo ano, o agronegócio representou 21,46\% do PIB brasileiro e com boas perspectivas para o ano de 2016. Diante desse cenário, o objetivo desse estudo é investigar as características das cooperativas agropecuárias paranaenses com tipificações de cultura organizacional predominantes (Cameron e Quinn, 2006) e os níveis de práticas de contabilidade gerencial semelhantes. Foi realizado survey com os contadores gerenciais das cooperativas agropecuárias paranaenses a fim de se atingir o objetivo central da pesquisa a partir da construção do marco teórico-empírico baseado em diversos autores e

\footnotetext{
${ }^{1}$ Artigo recebido em 09/02/2017. Revisado por pares em 22/05/2018. Reformulado em 11/06/2018. Recomendado para publicação em 27/11/2018 por Franciele Beck. Publicado em XX/XX/2018. Organização responsável pelo periódico: FURB.
} 
respectiva criação de 4 proposições relacionadas a cada tipificação cultural. Os resultados demonstraram que, de acordo com a base empírica utilizada, há todos os estágios de práticas de contabilidade gerencial, com a predominância de ferramentas mais tradicionais, como rateio dos custos, orçamentos flexíveis e payback para investimentos de capital. Foram identificadas tipificações culturais grupais, hierárquicas e de mercado conforme modelo utilizado de Cameron e Quinn (2006). A ausência da cultura inovativa direcionou a rejeição da proposição P3. Por fim, foram realizadas análises de agrupamentos das cooperativas com a finalidade de demonstrar por meio dos 3 clusters identificados que existem características conjuntas entre práticas de contabilidade gerencial e cultura organizacional, aceitando-se assim as proposições P1, P2 e P4.

Palavras-chave: Contabilidade Gerencial; Cultura Organizacional; Agronegócio; Cooperativismo.

\section{ABSTRACT}

Despite the economic recession that has spread through Brazil after the year 2015, resulting in a 3.8\% negative Gross Domestic Product, the farming cooperatives of the Paraná State have attained a $20 \%$ growth in their income values, besides representative margins (OCB, 2016). In the same year, the agribusiness represented $21.46 \%$ of the Brazilian GDP and has excellent prospects for 2016. Within such a scenario, the objective of this study is to investigate the usage levels of management accounting practices in the farming cooperatives of Paraná, together with the identification of the prevailing organizational cultures (Cameron e Quinn, 2006). A survey was conducted with the management accountants of the farming cooperatives in Paraná to accomplish the central objective of the research based on the construction of the theoreticalempirical framework, on several authors and respective creation of 4 propositions related to each cultural typification. The results have shown that, according to the empirical base used, all stages of management accounting practices are present, with the predominance of the more traditional tools, like cost assessment rate, budget flexible and payback for the analysis of investiment capital. Regarding the organizational culture, group, hierarchical and market typifications were identified, according to the model used. The absence of the innovative culture led to the rejection of the $\mathrm{P} 3$ proposition. Finally, the cooperatives were grouped together with the intention of demonstrating the relationship between 3 identified clusters, that the management accounting practices and the organizational culture have joint characteristics, thus accepting the $\mathrm{P} 1, \mathrm{P} 2$ e $\mathrm{P} 4$ propositions.

Keywords: Management Accounting; Organizational Culture; Agribusiness; Cooperativism.

\section{RESUMEN}

A pesar de la recesión económica que asoló Brasil a partir del año 2015, que resultó en un Producto Interno Bruto negativo de 3,8\%, las cooperativas agropecuarias del Estado de Paraná obtuvieron un crecimiento del $20 \%$ en el valor de sus paquetes de ventas, además de excedentes representativos (OCB, 2016). En el mismo año, el agronegocio representó 21,46\% del PIB brasileño y con buenas perspectivas para el año 2016. Delante de este escenario, el objetivo de este estudio es investigar si las cooperativas agropecuarias paranaenses con caracterizaciones de cultura organizacional predominantes (Cameron e Quinn, 2006), tienden a utilizar niveles de prácticas de contabilidad gerencial semejantes. Fue realizado survey con los contadores gerenciales de las cooperativas agropecuarias paranaenses, a fin de cumplirse el objetivo central de la investigación, a partir de la construcción del marco teórico-empírico basado en diversos autores y la respectiva creación de 4 proposiciones relacionadas a cada caracterización cultural. Los resultados demostraron que, de acuerdo con la base empírica utilizada, hay todas las fases de prácticas de contabilidad gerencial, con la predominancia de herramientas más tradicionales 
como tasa de evaluación de costos, presupuesto flexible y recuperación de la inversión para el análisis del capital de inversión. Fueron identificadas caracterizaciones culturales grupales, jerárquicas y de mercado conforme al modelo utilizado. La ausencia de la cultura innovadora direccionó al abandono de la proposición P3. Por fin, fueron realizados análisis de agrupamientos de las cooperativas con la finalidad de demostrar por medio de los 3 clusters identificados que existen características conjuntas entre prácticas de contabilidad gerencial e cultura organizacional, aceptándose así las proposiciones P1, P2 y P4.

Palabras-clave: Contabilidad Gerencial; Cultura Organizacional; Agronegocio; Cooperativismo.

\section{INTRODUÇÃO}

O que determina ou influencia as práticas de contabilidade gerencial das empresas e seus respectivos 'níveis de sofisticação'? O questionamento contextualiza uma temática que necessita, de modo constante e dinâmico, investigações científicas com o objetivo de proporcionar um melhor entendimento e o contínuo aperfeiçoamento de tais práticas que acompanham o cotidiano das empresas no mundo (ANTHONY; GOVINDARAJAN, 1987; JOHNSON; KAPLAN, 1993; ABDEL-KADER; LUTHER, 2008). As últimas décadas foram marcadas pela construção de modelos de análises de práticas de contabilidade gerencial a partir de diversas abordagens e perspectivas, e que refletem em inúmeras investigações empíricas, porém, nem sempre suficientes (MALMI, 2010; AHRENS et al., 2008).

Bromwich e Scapens (2016), a partir da análise dos últimos 25 anos de publicação da European Accounting Review, demonstraram um amplo crescimento das pesquisas em sistemas de controles gerenciais, entre outras áreas. Mas tal elevação de investigações, na visão dos autores, tem como oportunidades e desafios a aproximação à realidade, ou seja, a prática. $\mathrm{Na}$ mesma direção Cooper (2015) analisou a evolução do controle gerencial a partir das publicações da Accounting, Organizations and Society desde 1976, também mencionando a relevância da prática.

Compreender, por exemplo, a partir de estudos empíricos, as práticas de contabilidade gerencial de empresas que se destacam no cenário econômico de uma nação, torna-se relevante. Aliar a análise de tais práticas a outros aspectos como as características culturais predominantes em uma organização permitem identificar possibilidades de estudos futuros e contínuos, tendo em vista que o tema da cultura organizacional oferece um amplo campo de relações com essas práticas de gestão conforme anteriormente já estudado (HENRI, 2006; AHRENS; MOLLONA, 2007; BUSCO; SCAPENS, 2011). Geertz (1926) já afirmava que a cultura remete a uma 'teia de significados' tecida pelo próprio homem. Nessa perspectiva, Hofstede (1985) e Schein (1992) direcionaram a cultura para o contexto organizacional, demonstrando que a mesma influencia e pode ser influenciada pelas práticas humanas e estruturas de crenças e valores nas organizações. No ambiente contábil, Dent (1991) já mencionava o pouco conhecimento sobre como a contabilidade refletia na cultura organizacional. Estudos anteriores demonstraram que há essa relação e que ela ainda carece de investigações mais específicas (SOETERS; SCHREUDER, 1988; CHOW; SHIELDS; WU, 1999; CHOW; HARRISON; MCKINNON; WU, 2002; VAN DER STEDE, 2003; HOFSTEDE, 2003; HENRI, 2006; AHRENS; MOLLONA, 2007; BUSCO; SCAPENS, 2011; AX; GREVE, 2016).

Hofstede (1985) identificou as influências que a cultura de uma nação exerce sobre seu processo de gestão por meio de dimensões. Muitos anos após seu estudo original, Hofstede atualizou tais dimensões da cultura organizacional a partir do crescimento econômico da China e os respectivos reflexos das características culturais em outros países (MINKOV; HOFSTEDE, 2012). Porém, quando se fala em nações e suas culturas, é importante evidenciar aquilo que é 'genuinamente' ligado a um país. Ou seja, o que isso pode trazer de entendimentos 
que possam se tornar parâmetros ao crescimento e desenvolvimento de outras nações. Dessa forma, o presente estudo tenta realizar essa ligação específica entre cultura organizacional e práticas de contabilidade gerencial a partir do Competing Value Model de Cameron e Quinn (2006). Nesse modelo, a cultura de uma organização pode ser enquadrada em 4 tipificações: clã/grupal, inovativa, mercado/racional e hierárquica. Essa ligação torna-se relevante tendo em vista o setor agropecuário ser destacável e as cooperativas agroindustriais terem obtido resultados consideráveis em termos de movimentações econômico-financeiras nos últimos anos.

A agricultura pode ser destacada como uma das atividades mais representativas na economia brasileira. De acordo com dados do Ministério da Agricultura, Pecuária e Abastecimento (MAPA) brasileiro, o agronegócio representou 21,46\% do Produto Interno Bruto (PIB) nacional no ano de 2015 (MAPA, 2016). No Estado do Paraná, região sul do Brasil, esse valor foi ainda maior, representando 33\% do PIB paranaense (MAPA, 2016). Enquanto o PIB total brasileiro sofreu uma redução em 2015 no valor de $-3,8 \%$, o PIB do agronegócio fechou o ano no patamar positivo de $1,8 \%$, demonstrando também boas perspectivas para o ano de 2016 (MAPA, 2016).

No contexto do agronegócio brasileiro destacam-se as cooperativas (SANTOS; LONDERO, 2017). Conforme dados da Organização das Cooperativas Brasileiras (OCB), aproximadamente metade da produção agropecuária de alimentos transita pelas 1.543 cooperativas brasileiras que possuem quase 1 milhão de associados, gerando uma média de 180.000 empregos diretos (OCB, 2016). Em 2015, mesmo diante de um cenário de crise econômica no país, as cooperativas agropecuárias do Estado do Paraná obtiveram um crescimento de $19,5 \%$ em seus respectivos faturamentos, além de relevantes sobras a serem destinadas (OCB, 2016).

Com base na contextualização desenvolvida, a questão norteadora da pesquisa é: Quais as características entre as tipificações de cultura organizacional clã/grupal, inovativa, mercado/racional e hierárquica predominantes e os níveis de práticas de contabilidade gerencial das cooperativas agropecuárias paranaenses? O objetivo do presente estudo é investigar se as cooperativas agropecuárias paranaenses com tipificações de cultura organizacional predominantes tendem a utilizar níveis de práticas de contabilidade gerencial semelhantes, como forma de analisar se a alteração desses níveis se relaciona com as características culturais. Para tanto, foi realizada uma survey com as cooperativas agrícolas associadas à Organização das Cooperativas do Estado do Paraná (OCEPAR), em virtude da representatividade do setor no contexto do agronegócio nacional.

Além das perspectivas teóricas mencionadas anteriormente, a pesquisa utilizou para fins de investigação das práticas de contabilidade gerencial o estudo realizado por Abdel-Kader e Luther (2006), entre outros já adaptados no Brasil. Na análise da cultura organizacional foi utilizado o Competing Value Model (CVM) proposto por Cameron e Quinn (2006), onde por meio de dimensões específicas, permite-se tipificar tal cultura. Como forma da análise conjunta entre contabilidade gerencial e cultura organizacional, foi utilizada a análise de clusters a fim de observar possíveis agrupamentos entre as respectivas variáveis quantitativas e qualitativas das cooperativas.

O estudo é pautado na necessidade de compreender o setor do agronegócio cooperativista no que tange seus aspectos de práticas de contabilidade gerencial, tendo em vista a representatividade econômica e social apresentada, face a estudos já existentes, como o de Isidoro et al. (2012), que buscou analisar a utilização de artefatos de contabilidade gerencial nesse setor. As informações demonstraram que 2015 foi um ano desolador para o Brasil no contexto econômico e político. A retração econômica foi precedida de inúmeros escândalos nas esferas políticas e organizacionais que refletem cotidianamente no comportamento da população. As empresas brasileiras atualmente necessitam de uma readequação em suas 
estruturas organizacionais na finalidade de obterem melhores resultados e enfrentarem a devastadora crise econômica. Logo, compreender as práticas de contabilidade gerencial de organizações que estão na, 'contramão' da crise, torna-se uma possibilidade de verificar as influências desses aspectos a outras organizações.

A contribuição teórica do presente estudo é pautada nas críticas estabelecidas por autores como Cooper (2015) e Bromwich e Scapens (2016) de que a contabilidade gerencial, com base em anos e anos de pesquisas e modelos desenvolvidos, deve se aproximar cada vez mais da realidade e necessidade das organizações em um contexto prático, ou seja, dos ferramentais, artefatos ou ações efetivamente utilizadas pelas mesmas. Do ponto de vista econômico e social, o estudo explora as práticas de contabilidade gerencial, refletida na gestão, de um setor predominante no Brasil e suas respectivas possibilidades de auxílio ao crescimento e desenvolvimento do país, principalmente diante de um cenário 'nebuloso' e da constante busca de 'dias melhores'.

\section{MARCO TEÓRICO-EMPÍRICO E PROPOSIÇÕES}

Para fundamentar a pesquisa no contexto teórico e empírico, inicialmente é discutido o objeto do estudo que foi investigado, ou seja, as cooperativas agropecuárias brasileiras e a respectiva representatividade do setor do agronegócio. Na sequência, realiza-se um debate acerca das práticas de contabilidade gerencial no ambiente organizacional, desde seus aspectos evolutivos, até os estudos realizados. Na fase final de sustentação teórico-empírica e das proposições, a pesquisa traz a discussão do tema cultural também no contexto organizacional e suas possíveis relações com a contabilidade gerencial.

\subsection{O agronegócio cooperativo brasileiro}

O setor do agronegócio no Brasil é responsável por boa parte dos alimentos consumidos no país, além de ser parte integrante dos alimentos também consumidos no restante do mundo. No ano de 2015 o setor foi responsável por $46 \%$ das exportações totais do país, atingindo um saldo positivo na balança comercial de US\$ 75,2 bilhões, face aos US\$ 19,7 bilhões do saldo total influenciados negativamente por outros setores (MAPA, 2016).

De acordo com Vieira Filho (2014), o Brasil 'rural' pode ser compreendido historicamente por três momentos específicos de expansão das fronteiras agrícolas. A compreensão desse aspecto histórico torna-se relevante em virtude das organizações diretamente ligadas ao setor do agronegócio também terem acompanhado tal evolução. Nos dias atuais praticamente todas as regiões do Brasil são produtoras no setor agropecuário, tanto em pequena, quanto em grande escala. Essa expansão justifica porque o setor representou no ano de 2015 21,46\% do PIB do país (MAPA, 2016).

$\mathrm{Na}$ evolução mundial, o cooperativismo surgiu como forma de atender aspectos sociais e econômicos no contexto da coletividade, sendo um meio pelo qual os cooperados podem ao mesmo tempo gerir as entidades e ainda obter diversos benefícios (ICA, 2016). Além da discussão voltada aos sete princípios originais, o cooperativismo deve ser pesquisado como um modo de gestão que sofreu notórias transformações ao longo dos anos. Nas mais diversificadas regiões brasileiras, um dos ramos de cooperação de maior destaque tem como base a predominância da atividade agroindustrial.

O atual modelo cooperativista agroindustrial de gestão gera um amplo debate no aspecto de sua aproximação com o modelo corporativo, onde as práticas gerenciais mais apuradas são uma necessidade real para a elevação dos ganhos de escala (COOK; CHADDAD; ILIOPOULUS, 2004). O setor demonstra ano após ano os amplos resultados positivos alcançados, firmando-se como um sistema sólido e contributivo ao crescimento econômico e desenvolvimento mundial (ALTMAN, 2015). Porém, para que esse sistema continue gerando 
bons números, torna-se imprescindível investigar quais são as atuais práticas contábeis de gestão, levando-se em conta aspectos exógenos de mercado e endógenos de processo como ferramentais específicos de controle.

Isidoro et al. (2012) identificaram as ferramentas gerenciais utilizadas pelas maiores cooperativas do setor do agronegócio à época fazendo relação específica com o desempenho das mesmas. Os resultados demonstraram que não há essa relação e que a maioria das cooperativas ainda estão em estágios intermediários de utilização de artefatos de contabilidade gerencial. De modo mais recente, Santos e Lohdero (2017) debateram os aspectos inerentes aos ICPC 14 aplicável às cooperativas brasileiras e mencionaram que o setor ainda necessita de estudos mais aprofundados para melhor compreensão da situação patrimonial das sociedades cooperativas.

\subsection{Práticas de contabilidade gerencial no ambiente organizacional}

Nos anos 1990 Johnson e Kaplan mencionavam que o ambiente econômico contemporâneo exigia "excelência dos sistemas corporativos de contabilidade gerencial" (JOHNSON; KAPLAN, 1993). Mais de vinte anos depois, a necessidade de excelência mantém-se contemporânea e crescente. Ou seja, no constante processo evolutivo, competitivo e tecnológico, a contabilidade gerencial necessita prestar informações precisas, recentes e aprofundadas para que as diferentes atividades organizacionais possam evoluir, bem como a administração consiga tomar as melhores decisões nos momentos ideais. Conforme contextualizado, pesquisas recentes demonstram que ainda há um amplo leque a ser investigado sobre a aplicabilidade de toda teoria já apresentada em contabilidade gerencial (BROMWICH; SCAPENS, 2016; COOPER, 2015).

A identificação dos estágios da contabilidade gerencial em uma organização, conforme os conceitos estabelecidos pelo IFAC no ano de 1998 se tornou relevante desde então, tendo em vista a análise do nível de utilização de ferramentas de controle específicas às entidades. $\mathrm{O}$ IFAC (1998) identificou e relacionou a evolução da contabilidade gerencial por meio de quatro estágios: Estágio 1 - Antes de 1950, onde o foco era a determinação do custo e controle financeiro, através do uso das tecnologias de orçamento e contabilidade de custos; Estágio 2 Por volta de 1965, onde o foco foi mudado para o fornecimento de informação para o controle e planejamento gerencial, através do uso de tecnologias como análise de decisão e contabilidade por responsabilidade; Estágio 3 - Por volta de 1994, onde a atenção foi focada na redução do desperdício de recursos usados nos processos de negócios, através do uso das tecnologias de análise do processo e administração estratégica de custos; Estágio 4 - Por volta de 1995, onde a atenção foi mudada para a geração ou criação de valor através do uso efetivo dos recursos, através do uso de tecnologias como exame dos direcionadores de valor ao cliente, valor para o acionista, e inovação organizacional (IFAC, 1998).

A partir de então diversos estudos foram realizados a fim de identificar as práticas de contabilidade gerencial nas organizações e seus respectivos estágios evolutivos, além de relacioná-los com diferentes aspectos organizacionais. Entre esses estudos destaca-se a pesquisa realizada por Abdel-Kader e Luther (2006). Os autores investigaram as práticas de contabilidade gerencial em indústrias de comida e bebida do Reino Unido, explorando o nível de 'sofisticação' de tais práticas. Os achados demonstraram que tais práticas ainda não eram particularmente sofisticadas e que deveriam ser mais disseminadas em termos de conceitos e técnicas (ABDEL-KADER; LUTHER, 2006). A base empírica da presente investigação toma como parâmetro o estudo de Abdel-Kader e Luther (2006), mas com adaptações específicas ao cenário brasileiro. Como o estudo dos autores inicia-se com a identificação de características específicas do setor alimentício britânico, a adaptação fez-se necessária.

No Brasil, pesquisas também demonstraram achados semelhantes. Isidoro et al. (2012) realizaram estudo específico em cooperativas agropecuárias paranaenses, demonstrando que 
apenas $13 \%$ das entidades objeto do estudo possuem contabilidade gerencial identificada no Estágio 4 estabelecido pelo IFAC (1998). Bialoskorski Neto, Barroso e Rezende (2012), com base na análise de cinco grandes cooperativas agroindustriais, demonstraram que quanto melhor os sistemas de controles gerenciais das mesmas, maior a possibilidade de redução dos custos de agência, ou seja, que tais sistemas devem apoiar o fluxo de monitoração, tanto minimizando assimetria de informações quanto prestando suporte às obrigações organizacionais. Já Guerreiro, Cornachione Jr. e Soutes (2011) demonstraram que empresas brasileiras de rankings de excelência utilizam artefatos modernos de contabilidade gerencial.

Teixeira et al. (2011) identificaram que empresas do estado do Espírito Santo utilizam ferramentas tradicionais e modernas de contabilidade gerencial, bem como sugeriram uma fraca associação entre desempenho econômico e as ferramentas tradicionais. Grande e Beuren (2011) analisaram que os 4 estágios evolutivos da contabilidade gerencial estão presentes nos Relatórios de Administração de uma empresa familiar de capital aberto brasileira. De modo mais específico às cooperativas agropecuárias, Reis e Teixeira (2013) identificaram a utilização de artefatos tradicionais e modernos nessas entidades do estado de Minas Gerais, porém, sem relação com desempenho e porte.

\subsection{A cultura organizacional e o Competing Value Model}

Para que se possa analisar a relevância do conhecimento das características culturais no ambiente cooperativo em virtude de sua representatividade, deve-se refletir acerca da própria cultura das organizações. Para Schein (1992), a cultura ajuda a iluminar a situação da organização, buscando, nos aspectos relacionados ao comportamento individual e coletivo, as respostas sobre as influências culturais existentes. O autor defende que a cultura de uma organização é um conjunto de pressuposições básicas compartilhadas (SCHEIN, 1992). Hofstede (1985) também se destacou nos estudos sobre a cultura organizacional a partir de casos desenvolvidos ainda na década de 1970 em empresas com atuação internacional. O autor criou cinco dimensões de análise para diagnosticar influências culturais na gestão organizacional e conseguiu identificar as principais predominâncias dessas características culturais em uma mesma empresa; porém, com atuação em diferentes países (HOFSTEDE, 1994).

Recentemente Minkov e Hofstede (2012) atualizaram o estudo sobre as cinco dimensões de cultura organizacional. Comparando também organizações em seus diferentes países de atuação, os autores identificaram que, a partir do crescimento econômico predominante na China nos últimos anos, muitos países do Ocidente já apresentam características de cultura organizacional a partir de dimensões de valores semelhantes.

A presença de características de cultura nacional e até regional pode envolver os elementos que moldam o processo de gestão de uma organização. Conforme abordado na contextualização, Dent (1991) analisou o pouco conhecimento sobre como a contabilidade reflete na cultura de uma organização, partindo do pressuposto que as organizações possuem propriedades culturais particulares. Henri (2006) e Ax e Grave (2016) também fizeram estudos no mesmo contexto. No contexto de Hofstede (1985) sobre as implicações da cultura nacional em organizações, Soeters e Schreuder (1988) identificaram tais influências em empresas de contabilidade. Os estudos de Chow et al. (1999), Chow et al. (2002), Van der Stede (2003) e Hofstede (2003), seguiram o mesmo direcionamento dessa influência.

No contexto da contabilidade gerencial, Busco e Scapens (2011) analisaram as relações entre os sistemas de controle gerenciais e cultura organizacional nos processos de mudança a partir do modelo original proposto por Burns e Scapens (2000). Ahrens e Mollona (2007) trouxeram de modo mais específico a discussão de que os controles gerenciais são uma prática cultural. 

COOPERATIVO

A proposta de relacionar práticas de contabilidade gerencial com aspectos de cultura organizacional partirá do modelo empírico elaborado por Cameron e Quinn (2006) de tipificação de culturas de empresas. O Competing Value Model (CVM) parte do questionamento junto aos indivíduos da organização sobre seis dimensões que tendem a caracterizar a cultura interna: as características dominantes; a liderança organizacional; o gerenciamento de pessoas e equipes; os aspectos de união organizacional; as caraterísticas voltadas à estratégia; e as características de sucesso da organização. Cada dimensão relacionada possui quatro características passíveis de atribuição de um score. Ao final, esses scores são calculados e demonstram em qual quadrante classificatório de cultura a organização está inserida (Figura 1).

Figura 1 - Modelo de Valores Competitivos.

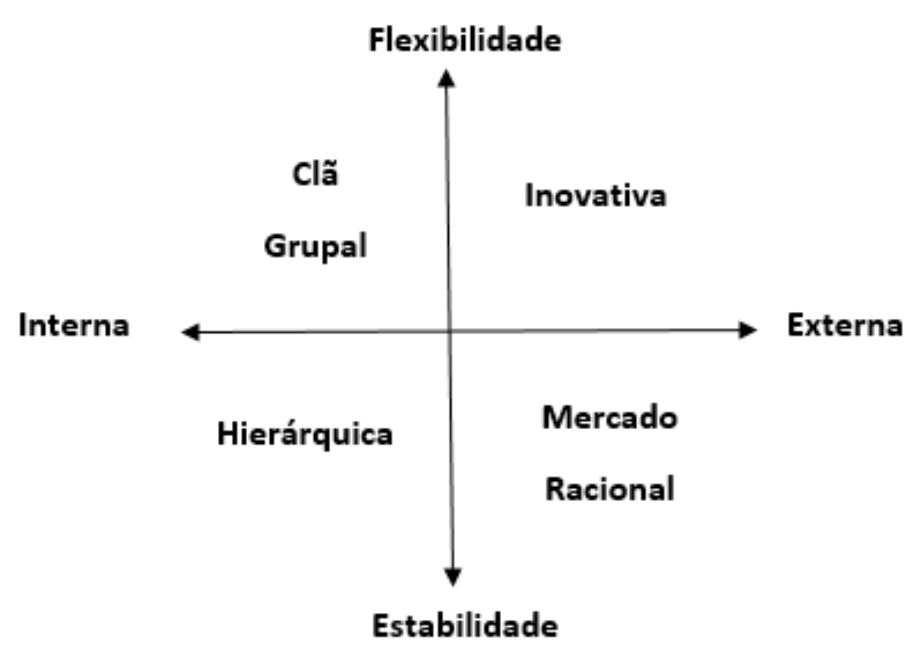

Fonte: Adaptado de Cameron e Quinn (2006, p.35).

No modelo apresentado são destacados quatro grupos que, conforme a aplicabilidade da análise, oferecem a classificação geral do tipo de cultura organizacional: clã/grupal, inovativa, mercado/racional e hierárquica. Os quatro grupos de valores organizacionais representam a oposição relativa aos modelos explicativos de eficácia organizacional, ou seja, a competição entre esses. Os quatro valores competitivos apresentados pelo modelo levam em consideração os seis aspectos principais apresentados e determinam qual a tendência de tipificação cultural da organização. Ou seja, a predominância de cada característica observada nas seis dimensões do modelo permite que seja identificado uma tendência de cultura organizacional. Dessa forma, após essa identificação, é possível sua respectiva relação e reflexão com as práticas de contabilidade gerencial.

A cultura grupal ou clã no quadrante superior à esquerda, detém a denominação devido a similaridade às organizações familiares. As principais características desta cultura são: valorização na participação dos membros da organização nas tomadas de decisão, trabalho em equipe, desenvolvimento de recursos humanos, dentre outras. A cultura inovativa, presente no quadrante direito e superior, tem a característica voltada ao processo de inovação face aos conhecimentos externos. Nesse modelo de cultura organizacional a liderança assume o perfil de criatividade, motivação e diversificação nas operações realizadas. No quadrante esquerdo e inferior, a cultura hierárquica é caracterizada pelos fatores motivacionais, burocráticos e conservadores no comportamento das organizações. O quarto e último modelo destacado no quadrante inferior direito é a cultura de mercado, focada à competitividade e produtividade como elementos de influência da organização. 


\subsection{Proposições de pesquisa a partir do marco teórico-empírico}

Alinhado às tipologias culturais, no desenvolvimento do estudo proposto serão analisadas as seguintes proposições de pesquisa: P1) Cooperativas agroindustriais com cultura organizacional caracterizada como grupal possuem níveis de práticas de contabilidade gerencial distintos às demais tipificações; P2) Cooperativas agroindustriais com cultura organizacional caracterizada como hierárquica possuem níveis de práticas de contabilidade gerencial distintos às demais tipificações; P3) Cooperativas agroindustriais com cultura organizacional caracterizada como inovadora possuem níveis de práticas de contabilidade gerencial distintos às demais tipificações; P4) Cooperativas agroindustriais com cultura organizacional caracterizada como de mercado possuem níveis de práticas de contabilidade gerencial distintos às demais tipificações.

\section{METODOLOGIA}

$\mathrm{Na}$ metodologia serão apresentados os métodos de coleta de dados, a amostra, o questionário eletrônico utilizado para a survey e a proposta de como os dados serão analisados na próxima seção.

\subsection{Método de coleta de dados e amostra}

Conforme mencionado na contextualização, as cooperativas selecionadas para o estudo foram as 64 organizações do setor agropecuário associadas à Organização das Cooperativas do Estado do Paraná (OCEPAR). Criado em 1971, o denominado Sistema OCEPAR é formado por três sociedades distintas, sem fins lucrativos que se dedicam à representação, fomento, desenvolvimento, capacitação e promoção social das cooperativas paranaenses: o Sindicato e Organização das Cooperativas do Estado do Paraná (OCEPAR), o Serviço Nacional de Aprendizagem do Cooperativismo (SESCOOP/PR) e a Federação e Organização das Cooperativas do Estado do Paraná (FECOOPAR).

A análise da viabilidade da pesquisa, bem como as informações necessárias aos procedimentos e bases de dados das cooperativas, se deu a partir de contato e reunião desenvolvida com o Coordenador de Desenvolvimento Cooperativo, com o Gerente de Autogestão e com o Gerente de Desenvolvimento Humano da OCEPAR. Posteriormente, também foi estabelecido contato com o Analista Técnico Especializado da OCEPAR com o objetivo de estabelecer os procedimentos finais necessários a survey.

Para fins de coleta de dados, foi criado um questionário eletrônico na plataforma SurveyMonkey@, encaminhado os respectivos links via email e estabelecido contato telefônico com os contadores gerenciais das 64 cooperativas entre os meses de outubro e novembro de 2016 conforme base de dados fornecida. No contato realizado destacaram-se os objetivos do estudo, a forma de preenchimento do questionário e a importância da pesquisa para o setor cooperativista. Após esse processo, chegou-se a um retorno de 37 questionários totalmente preenchidos, ou seja, aproximadamente $58 \%$ da amostra previamente estabelecida. Os detalhamentos dessas cooperativas são apresentados na seção 4, de modo mais específico na Tabela 1.

\subsection{Instrumento de coleta de dados}

Para atingir o objetivo proposto, o questionário foi desenvolvido em três partes principais: Parte I - Práticas de Contabilidade Gerencial; Parte II - Cultura Organizacional; e Parte III - Dados Demográficos. Atendendo a proposta de Abdel-Kader e Luther (2006) em que a pesquisa se baseou parcialmente, a Parte I utilizou uma escala em que os gestores classificavam a frequência de utilização das práticas de contabilidade gerencial nos painéis de 
sistemas de custos, prática orçamentária, avaliação de desempenho e informações para tomada de decisões, em: nunca, raramente, algumas vezes, frequentemente e muito frequentemente.

Ainda na Parte I, as questões 1.1 a 1.25 referiram-se especificamente às práticas de contabilidade gerencial estabelecidas por Abdel-Kader e Luther (2006) e pelo estudo brasileiro de Guerreiro, Cornachione Jr. e Soutes (2011). As questões de 1.26 a 1.30 trouxeram, a partir do marco teórico-empírico estabelecido, características de institucionalização das práticas e influências do cenário externo às mesmas, baseadas em estudos como os de Burns e Scapens (2000) e Busco e Scapens (2011). A Parte II do questionário foi dedicada à tipificação de cultura organizacional das cooperativas a partir da visão dos contadores gerenciais, com base no modelo de Cameron e Quinn (2006) anteriormente abordado. Para cada uma das seis dimensões foram criadas quatro questões extraídas do modelo, totalizando vinte e quatro perguntas, onde os respondentes também marcaram opções em uma escala semelhante à Parte I. Conforme as regras do modelo, após as análises das opções assinaladas nas questões 2.1 a 2.24, foi possível tipificar a cultura organizacional predominante na contabilidade gerencial das cooperativas.

Por fim, a Parte III do questionário foi dedicada a levantar o perfil dos respondentes e da organização cooperativa em aspectos específicos que não os identificassem individualmente, de acordo com os preceitos éticos estabelecidos na etapa de planejamento da coleta dos dados. A seção foi dividida em oito questões centrais de múltipla escolha a fim de se observar as seguintes informações: idade do respondente, gênero, grau de instrução, área de atuação específica na cooperativa, tempo de atuação na cooperativa, quantidade de funcionários diretos estimados, tempo de fundação da cooperativa e, como última informação solicitada, um campo para preenchimento opcional do email para recepção dos resultados gerais da investigação.

\subsection{Proposta de análise dos dados}

As análises realizadas na seção seguinte foram separadas em três etapas. As duas primeiras etapas se utilizaram de estatística descritiva e a terceira propõe agrupar as cooperativas a partir das características conjuntas de contabilidade gerencial e de cultura organizacional observadas. A primeira etapa analisou o nível de utilização das práticas de contabilidade gerencial pelas cooperativas por meio das frequências estabelecidas pelas médias observadas em cada questão, ou seja, da não utilização até a alta frequência de utilização. Para fins de melhor acurácia aos números encontrados serão utilizados os cálculos de desvio padrão e de variância das respostas analisadas. Para tanto, como ferramenta de análise foi utilizado o software SPSS ${ }^{\circledR}$ versão 17.0. Após analisadas as características das práticas, foi possível classificar as 37 cooperativas em um dos quatro estágios evolutivos de contabilidade gerencial estabelecidos pelo IFAC (1998), tendo em vista a predominância do próprio modelo de análise a partir da frequência de utilização das ferramentas gerenciais.

A segunda etapa analisou a tipificação de cultura organizacional predominante em cada cooperativa investigada. Conforme o CVM, cada uma das 37 cooperativas respondentes obteve um tipo de cultura organizacional estabelecida entre grupal, inovativa, mercado ou hierárquica. Como ferramenta de organização para as respectivas análises, também foi utilizado o software SPSS® versão 17.0, a partir das técnicas de estatística descritiva necessárias.

Analisadas as duas primeiras etapas, a terceira etapa teve como objetivo final propor agrupamentos específicos das 37 cooperativas a partir da junção entre os estágios evolutivos de contabilidade gerencial e as tipificações de cultura organizacional. O objetivo central de uma análise por agrupamentos ou conglomerados é, a partir de características semelhantes, verificar se há semelhança entre determinado grupo de objetos. Caso haja essa semelhança, os objetos podem ser agrupados por meio de uma análise mais específica. A ferramenta utilizada para as respectivas análises é o software NVIVO ${ }^{\circledR}$ versão 11 , em virtude da possibilidade de relacionamento de variáveis qualitativas estabelecidas nas proposições da pesquisa, ou seja, o processo identifica tais grupos a partir dos agrupamentos de palavras relacionadas às 
características de cultura organizacional e práticas de contabilidade gerencial.

Nas conclusões o estudo traz, entre outros aspectos, possibilidades de emprego de análises estatísticas mais aprofundadas caso a amostra seja ampliada a outras cooperativas de outros estados brasileiros.

\section{RESULTADOS DA SURVEY E ANÁLISE DOS DADOS}

Três análises descritivas serão desenvolvidas: as práticas de contabilidade gerencial, a cultura organizacional e os possíveis agrupamentos das cooperativas. Inicialmente cabe ressaltar a necessidade de uma análise descritiva do perfil dos respondentes e das próprias organizações cooperativas. Em relação ao perfil do respondente, foram levantadas informações acerca da idade, gênero, grau de instrução, área específica e tempo de atuação na empresa. Já em relação ao perfil da cooperativa, como forma de evitar qualquer tipo de identificação, as informações limitaram-se na quantidade média de funcionários e o tempo de fundação. Aspectos específicos como a quantidade de cooperados e faturamento foram preservados conforme reuniões prévias junto à OCEPAR.

Tabela 1 - Perfil dos respondentes e da cooperativa.

\begin{tabular}{|c|c|c|c|c|c|c|c|}
\hline \multirow[t]{2}{*}{ Idade } & 21 a 30 & 31 a 40 & 41 a 50 & 51 a 60 & & & \\
\hline & $19 \%$ & $24,3 \%$ & $43,2 \%$ & $13,5 \%$ & & & \\
\hline \multirow[t]{2}{*}{ Gênero } & Masculino & Feminino & & & & & \\
\hline & $78 \%$ & $22 \%$ & & & & & \\
\hline \multirow[t]{2}{*}{ Instrução } & Grad. & Esp./MBA & Mestrado & & & & \\
\hline & $27 \%$ & $70,3 \%$ & $2,7 \%$ & & & & \\
\hline \multirow[t]{2}{*}{ Área } & Contábil & Outras & & & & & \\
\hline & $89 \%$ & $11 \%$ & & & & & \\
\hline \multirow[t]{2}{*}{ Atuação(anos) } & 1 a 5 & 5 a 10 & 10 a 20 & 20 a 30 & sup. 30 & & \\
\hline & $32,4 \%$ & $29,7 \%$ & $24,3 \%$ & $5,5 \%$ & $8,1 \%$ & & \\
\hline \multirow[t]{2}{*}{ Funcionários } & 1 a 100 & 101 a 500 & 501 a 1000 & 1001 a 3000 & 3001 a 5000 & sup. 5000 & \\
\hline & $56,8 \%$ & $13,5 \%$ & $5,4 \%$ & $21,6 \%$ & - & $2,7 \%$ & \\
\hline \multirow[t]{2}{*}{ Fundação(anos) } & 1 a 5 & 5 a 10 & 10 a 20 & 20 a 30 & 30 a 40 & 40 a 50 & sup. 50 \\
\hline & $5,4 \%$ & $10,8 \%$ & $27 \%$ & $13,5 \%$ & $8,2 \%$ & $2,7 \%$ & $32,4 \%$ \\
\hline
\end{tabular}

Fonte: dados da pesquisa.

A idade predominante dos respondentes é entre 31 e 50 anos; $78 \%$ do gênero masculino; 70,3\% com especialização; 89\% específicos da área contábil; e 86\% atuando na cooperativa entre 1 e 20 anos. A Tabela 1 apresenta, com alguns destaques específicos, uma diversificação tanto no perfil dos respondentes em relação à idade, gênero, formação, área de atuação, tempo de atuação, quanto no porte e estrutura das cooperativas em relação a quantidade de funcionários e tempo de fundação. Essa diversificação é relevante ao contexto da investigação, tendo em vista não haver uma tendência específica de perfil de cooperativa na amostra, o que contribui de maneira direta para os achados do estudo. Ou seja, mesmo identificando-se cooperativas com grandes estruturas administrativas, as consideradas médias e pequenas também compuseram a amostra do estudo.

\subsection{Práticas de contabilidade gerencial}

Nessa etapa de análise, foram tabulados os dados a partir da survey e as práticas de contabilidade gerencial foram observadas em duas etapas distintas: a primeira com base nas perguntas direcionadas às cooperativas na parte I do questionário e a segunda como uma 

COOPERATIVO

proposta de classificação das 37 organizações conforme os estágios evolutivos de contabilidade gerencial do IFAC (1998). De acordo com a seção 3.2 as práticas foram analisadas em quatro subgrupos específicos ao marco teórico utilizado: sistemas de custos, orçamento, análise de desempenho e informação para tomada de decisão. $O$ quinto subgrupo, denominado características institucionais, foi criado a partir da necessidade de relacionar aspectos vinculados ao processo de institucionalização de determinadas práticas, bem como a fatores exógenos que podem influenciar tal processo. A média foi calculada com base na estrutura do instrumento de coleta de dados aplicado cuja escala destacou um mínimo de 1 e máximo de 5 , com cálculos sequentes de desvio padrão e variância.

Tabela 2 - Sistemas de custos.

\begin{tabular}{lccc}
\hline & Média & D.Padrão & Variância \\
\hline $\begin{array}{l}\text { 1.1. A cooperativa classifica os seus custos em } \\
\text { fixos/variáveis/diretos/indiretos* }\end{array}$ & 3,81 & 1,288 & 1,658 \\
\hline 1.2. A cooperativa utiliza taxa de rateio dos custos* & 3,54 & 1,26 & 1,589 \\
\hline $\begin{array}{l}\text { 1.3. A cooperativa apura custos por departamentos* } \\
\text { 1.4. A cooperativa utiliza técnicas estatísticas para } \\
\text { apuração dos custos* }\end{array}$ & 3,81 & 1,33 & 1,769 \\
\hline $\begin{array}{l}\text { 1.5. A cooperativa utiliza o Custeio por Absorção** } \\
\text { 1.6. A cooperativa utiliza o Custeio Variável** }\end{array}$ & 2,78 & 1,456 & 2,119 \\
\hline 1.7. A cooperativa utiliza o Custo Padrão** & 2,35 & 1,379 & 1,901 \\
\hline $\begin{array}{l}\text { 1.8. A cooperativa utiliza o Custeio Baseado em } \\
\text { Atividades (ABC)* }\end{array}$ & 2,19 & 1,379 & 1,901 \\
\hline 1.9. A cooperativa utiliza o Custeio Alvo* & 2,03 & 1,371 & 1,88 \\
\hline
\end{tabular}

*baseado em Abdel-Kader e Luther (2006)

**baseado em Guerreiro, Cornachione Jr. e Soutes (2011)

Fonte: dados da pesquisa.

A maior parte das cooperativas paranaenses utiliza o orçamento para decisões de longo prazo, controle de custos e análise de variações conforme as médias apresentadas na Tabela 3. Já na divisão por atividades, observa-se também uma alta predominância de utilização, porém de forma mais equilibrada tendo em vista a diferença de porte entre as cooperativas. Há adaptabilidade à flexibilização do orçamento conforme necessidade durante o período, porém há baixa predominância da utilização orçamento base zero.

Tabela 3 - Orçamento

\begin{tabular}{lccc}
\hline & Média & D.Padrão & Variância \\
\hline $\begin{array}{l}\text { 1.10. A cooperativa utiliza o orçamento para } \\
\text { planejamento de longo prazo* }\end{array}$ & 4,14 & 1,357 & 1,842 \\
\hline $\begin{array}{l}\text { 1.11. A cooperativa utiliza o orçamento para controle de } \\
\text { custos* }\end{array}$ & 3,97 & 1,258 & 1,583 \\
\hline $\begin{array}{l}\text { 1.12. A cooperativa utiliza o orçamento individualizado } \\
\text { por atividades* }\end{array}$ & 3,22 & 1,652 & 2,73 \\
\hline $\begin{array}{l}\text { 1.13. A cooperativa utiliza o orçamento para análise de } \\
\text { variações* }\end{array}$ & 3,7 & 1,614 & 2,604 \\
\hline $\begin{array}{l}\text { 1.14. A cooperativa utiliza o orçamento de modo flexível } \\
\text { a alterações que ocorram durante o período contemplado* }\end{array}$ & 3 & 1,453 & 2,111 \\
\hline $\begin{array}{l}\text { 1.15. A cooperativa utiliza o orçamento base zero - } \\
\text { sempre reiniciando os valores a cada período* }\end{array}$ & 2,27 & 1,387 & 1,925 \\
\hline
\end{tabular}

*baseado em Abdel-Kader e Luther (2006).

Fonte: dados da pesquisa. 
A maior parte das cooperativas paranaenses utiliza o orçamento para decisões de longo prazo, controle de custos e análise de variações conforme as médias apresentadas na Tabela 3. Já na divisão por atividades, observa-se também uma alta predominância de utilização, porém de forma mais equilibrada tendo em vista a diferença de porte entre as cooperativas. Há adaptabilidade à flexibilização do orçamento conforme necessidade durante o período, porém há baixa predominância da utilização orçamento base zero.

Tabela 4 - Avaliação de desempenho

\begin{tabular}{lccc}
\hline & Média & D.Padrão & Variância \\
\hline $\begin{array}{l}\text { 1.16. A cooperativa desenvolve e utiliza planejamento } \\
\text { estratégico** }\end{array}$ & 3,73 & 1,239 & 1,536 \\
\hline $\begin{array}{l}\text { 1.17. A cooperativa utiliza o Valor Econômico Agregado } \\
\text { (EVA) para análise* }\end{array}$ & 1,92 & 1,01 & 1,021 \\
\hline $\begin{array}{l}\text { 1.18. A cooperativa utiliza a análise custo / volume / } \\
\text { lucro* }\end{array}$ & 3,73 & 1,239 & 1,536 \\
\hline $\begin{array}{l}\text { 1.19. A cooperativa utiliza a análise de rentabilidade dos } \\
\text { produtos/serviços* }\end{array}$ & 4,05 & 1,129 & 1,275 \\
\hline $\begin{array}{l}\text { 1.20. A cooperativa utiliza padrões de análise baseada em } \\
\text { outras empresas (benchmarking)* }\end{array}$ & 3,27 & 1,427 & 2,036 \\
\hline
\end{tabular}

*baseado em Abdel-Kader e Luther (2006).

**baseado em Guerreiro, Cornachione Jr. e Soutes (2011).

Fonte: dados da pesquisa.

Para análise de desempenho, práticas como a análise custo/volume/lucro, análise de rentabilidade de produtos e serviços, bem como o planejamento estratégico aparecem de forma destacada pelas cooperativas. A utilização do benchmarking também aparece, porém de forma mais equilibrada. Tal fato pode ser oriundo de que a localização de algumas cooperativas pode não ser estratégica para esse fim, visto que algumas das entidades pesquisadas encontram-se em regiões específicas, isoladas em algum momento de entidades do mesmo setor. Já análises como o Economic Value Added são muito pouco utilizadas. Um dos fatores que podem explicar a baixa utilização dessa análise é o foco dela ser na lucratividade, fator não objetivado de forma central pelas cooperativas, ou seja, as sobras são consequências das diversas políticas de gestão adotadas.

Tabela 5 - Informação para tomada de decisão

\begin{tabular}{lccc}
\hline & Média & D.Padrão & Variância \\
\hline $\begin{array}{l}\text { 1.21. A cooperativa utiliza modelos de controle de } \\
\text { estoques* }\end{array}$ & 4,19 & 0,938 & 0,88 \\
\hline $\begin{array}{l}\text { 1.22. A cooperativa utiliza o fluxo de caixa descontado } \\
\text { para análise de investimentos de capital* }\end{array}$ & 3,16 & 1,068 & 1,14 \\
\hline $\begin{array}{l}\text { 1.23. A cooperativa utiliza o payback para análise de } \\
\text { investimentos de capital* }\end{array}$ & 3,08 & 1,341 & 1,799 \\
\hline $\begin{array}{l}\text { 1.24. A cooperativa utiliza simulações ou probabilidades } \\
\text { para análise de investimentos de capital* }\end{array}$ & 2,68 & 1,334 & 1,781 \\
\hline $\begin{array}{l}\text { 1.25. A cooperativa utiliza o modelo BSC (Balanced } \\
\text { Scorecard)** }\end{array}$ & 1,95 & 1,29 & 1,664 \\
\hline
\end{tabular}

*baseado em Abdel-Kader e Luther (2006).

**baseado em Guerreiro, Cornachione Jr. e Soutes (2011).

Fonte: dados da pesquisa.

Em relação às informações geradas pelas práticas de contabilidade gerencial para tomada de decisão, observa-se que a prática mais simplificada de controle de estoques é a mais utilizada. Utilização de simulações ou probabilidades para análise de investimentos de capital e utilização do Balanced Scorecard aparecem com baixas médias de opção. Já o fluxo de caixa 
descontado e o payback para análises de investimentos de capital aparecem como ferramentas utilizadas de forma mais discreta.

Tabela 6 - Características institucionais

\begin{tabular}{|c|c|c|c|}
\hline & Média & D.Padrão & Variância \\
\hline $\begin{array}{l}\text { 1.26. Fatores internos como clima e comportamento } \\
\text { organizacional influenciam positivamente as práticas de } \\
\text { contabilidade gerencial da cooperativa }\end{array}$ & 2,65 & 1,719 & 2,956 \\
\hline $\begin{array}{l}\text { 1.27. As práticas de contabilidade gerencial da cooperativa } \\
\text { sofrem constantes alterações }\end{array}$ & 3 & 0,972 & 0,944 \\
\hline $\begin{array}{l}\text { 1.28. As práticas de contabilidade gerencial da cooperativa } \\
\text { estão contempladas em manuais ou outros documentos }\end{array}$ & 2,89 & 1,308 & 1,71 \\
\hline $\begin{array}{l}\text { 1.29. A Lei } 12.973 / 2014 \text { que fixou regras específicas para a } \\
\text { escrituração contábil das cooperativas brasileiras refletiu } \\
\text { nas práticas de contabilidade gerencial }\end{array}$ & 3,49 & 1,193 & 1,423 \\
\hline $\begin{array}{l}\text { 1.30. A crise econômica que se estabeleceu no Brasil a } \\
\text { partir de } 2015 \text { refletiu nas práticas de contabilidade } \\
\text { gerencial da cooperativa }\end{array}$ & 3,32 & 1,107 & 1,225 \\
\hline
\end{tabular}

Fonte: dados da pesquisa.

As características institucionais tomaram como base as discussões realizadas por Burns e Scapens (2000) e Busco e Scapens (2011) no que tange o processo de institucionalização das práticas de contabilidade gerencial. Esse processo parte de um fator específico causado pelo ambiente endógeno ou exógeno à organização que venha a se tornar hábitos, rotinas, até a institucionalização de uma prática. Fatores endógenos como clima e comportamento, e contemplação das práticas gerenciais em manuais formais apresentaram valores abaixo da média. É relevante ressaltar que essas características podem influenciar o processo de institucionalização da contabilidade gerencial. Já fatores exógenos como a Lei 12.973/2014 que fixou regras contábeis específicas para as cooperativas brasileiras e a crise econômica nacional são fatores que influenciam diretamente tais práticas (Tabela 6).

Como análise final ao item 4.1, foram identificados os níveis dos estágios evolutivos da contabilidade gerencial das 37 cooperativas respondentes, apresentados na Tabela 7. Para fins de identificação dos estágios predominantes, foi utilizada média que variou de 1 a 5 . Observase uma predominância de práticas nos estágios 1 e 2 com médias gerais respectivas acima de 3 , onde a ênfase é estabelecida na determinação do custo, prática orçamentária e geração de informações específicas para tomada de decisão com a utilização de recursos tecnológicos. $\mathrm{Na}$ sequência, identifica-se as médias gerais inferiores a 3 para o estágio 3 e 4 , onde aspectos de gestão estratégica custos e geração de valor são destacados, conforme a descrição elaborada pelo IFAC (1998).

Em termos empíricos, essa pesquisa corrobora com os achados de Abdel-Kader e Luther (2006) no sentido de que ainda há uma lacuna existente entre a proposição de ferramentas mais apuradas de contabilidade gerencial e a efetiva utilização por parte das organizações em termos práticos. Observa-se que o nível de utilização das ferramentas de controle gerencial das cooperativas pesquisadas ainda é incipiente. Comparativamente a estudos anteriores no contexto brasileiro, a pesquisa também corrobora com o estudo de Isidoro et al. (2012) referente à utilização das práticas de contabilidade gerencial contempladas no estágio 4 ainda serem discretas. Já o estudo de Guerreiro, Cornachione Jr. e Soutes (2011) que identificou que as empresas da amostra pesquisada utilizavam artefatos modernos de contabilidade gerencial se equivaleu parcialmente aos achados da presente investigação, tendo em vista algumas cooperativas ainda terem baixa participação nos estágios 3 e 4 de evolução. 
Tabela 7 - Estágios de práticas de contabilidade gerencial

\begin{tabular}{|c|c|c|c|}
\hline ESTÁGIO 1 & Média & D.Padrão & Variância \\
\hline Taxa de rateio dos custos & 3,54 & 1,26 & 1,589 \\
\hline $\begin{array}{l}\text { Orçamento de modo flexível a alterações que ocorram } \\
\text { durante o período contemplado }\end{array}$ & 3 & 1,453 & 2,111 \\
\hline Payback para análise de investimentos de capital & 3,08 & 1,341 & 1,799 \\
\hline ESTÁGIO 2 & Média & D.Padrão & Variância \\
\hline Classificação dos custos em fixos/variáveis/diretos/indiretos & 3,81 & 1,288 & 1,658 \\
\hline Custos por departamentos & 3,81 & 1,33 & 1,769 \\
\hline Técnicas estatísticas para apuração dos custos & 2,78 & 1,456 & 2,119 \\
\hline Custeio por Absorção & 3,35 & 1,379 & 1,901 \\
\hline Custeio Variável & 2,35 & 1,379 & 1,901 \\
\hline Custo Padrão & 2,19 & 1,371 & 1,88 \\
\hline Orçamento para planejamento de longo prazo & 4,14 & 1,357 & 1,842 \\
\hline Orçamento para controle de custos & 3,97 & 1,258 & 1,583 \\
\hline Orçamento para análise de variações & 3,7 & 1,614 & 2,604 \\
\hline Análise custo/volume/lucro & 3,73 & 1,239 & 1,536 \\
\hline Análise de rentabilidade dos produtos/serviços & 4,05 & 1,129 & 1,275 \\
\hline Modelos de controle de estoques & 4,19 & 0,938 & 0,88 \\
\hline $\begin{array}{l}\text { Fluxo de caixa descontado para análise de investimentos de } \\
\text { capital }\end{array}$ & 3,16 & 1,068 & 1,14 \\
\hline ESTÁGIO 3 & Média & D.Padrão & Variância \\
\hline Custeio Baseado em Atividades (ABC) & 2,03 & 1,404 & 1,971 \\
\hline Orçamento individualizado por atividades & 3,22 & 1,652 & 2,73 \\
\hline Orçamento base zero & 2,27 & 1,387 & 1,925 \\
\hline ESTÁGIO 4 & Média & D.Padrão & Variância \\
\hline Custeio Alvo & 1,81 & 1,151 & 1,324 \\
\hline Planejamento estratégico & 3,73 & 1,239 & 1,536 \\
\hline Valor Econômico Agregado $(E V A)$ & 1,92 & 1,01 & 1,021 \\
\hline Benchmarking & 3,27 & 1,427 & 2,036 \\
\hline $\begin{array}{l}\text { Simulações ou probabilidades para análise de investimentos } \\
\text { de capital }\end{array}$ & 2,68 & 1,334 & 1,781 \\
\hline BSC (Balanced Scorecard) & 1,95 & 1,29 & 1,664 \\
\hline
\end{tabular}

Fonte: dados da pesquisa.

Pela representatividade das cooperativas que compõem a amostra, é possível afirmar que as cooperativas agropecuárias paranaenses se enquadram nos 4 estágios evolutivos da contabilidade gerencial segundo o IFAC (1998). Porém, quando se detalha a quantidade de cooperativas em uma escala de média, $59 \%$ se destacam no estágio $1 ; 76 \%$ no estágio $2 ; 38 \%$ no estágio 3; e $40 \%$ no estágio 4. Esses números demonstram que, mesmo em uma atividade voltada aos aspectos primários de produção agrícola, processamento e distribuição de produtos, há constante preocupação em utilização de ferramentas mais apuradas que se aproximam a práticas de multinacionais do setor. Porém, os resultados corroboram os achados, por exemplo, de Isidoro et. al. (2012) que apontaram a não utilização de artefatos mais avançados de contabilidade gerencial.

\subsection{Cultura organizacional e clusters das cooperativas}

Após a tabulação dos dados e as análises da segunda parte do questionário foi possível a identificação geral do tipo de cultura organizacional predominante em cada uma das 37 

COOPERATIVO

cooperativas em clã/grupal, inovativa, mercado/racional e hierárquica. Os quatro grupos de valores organizacionais representam a oposição relativa aos modelos explicativos de eficácia organizacional, ou seja, a competição entre esses. As tipificações gerais de cultura organizacional observada sob a ótica dos contadores gerenciais foram representadas na Tabela 8. Ressalta-se que tais tipificações foram possíveis a partir da aplicabilidade do Competing Value Model supra explorado, onde as respostas específicas ao modelo direcionam às características e tipificação cultural predominante.

Tabela 8 - Tipificação de cultura organizacional

\begin{tabular}{lcc}
\hline & Frequência & \% \\
\hline Clã/Grupal & 18 & 48,6 \\
\hline Inovativa & - & - \\
\hline Mercado/Racional & 7 & 18,9 \\
\hline Hierárquica & 12 & 32,5 \\
\hline
\end{tabular}

Fonte: dados da pesquisa.

Conforme o modelo CVM, 48,6\% das cooperativas agropecuárias paranaenses tiveram como cultura organizacional predominante a cultura clã, que também é denominada de grupal e detém a denominação devido à similaridade às organizações familiares. Para os autores, empresas com essa caracterização cultural tendem a ser uma extensão familiar, pois as relações humanas são muito presentes, bem como a lealdade entre os membros e o tradicionalismo. As principais características desta cultura são: valorização na participação dos membros da organização nas tomadas de decisão, trabalho em equipe, desenvolvimento de recursos humanos e consenso.

Pela Tabela 8 não foram observadas tipificações de cultura inovativa cuja característica é voltada ao processo de inovação face aos conhecimentos externos. Cameron e Quinn (2006) afirmam que, nesse modelo de cultura organizacional, estão presentes características de dinamismo, inovação, criatividade e fácil adaptabilidade às mudanças tecnológicas que são crescentes na era contemporânea. Tornando possível a modificação no que tange à cultura das organizações, esse modelo destaca-se pela flexibilidade e reestruturação referentes ao comportamento das empresas, porém não foi observado como predominante em nenhuma das 37 cooperativas.

De acordo com as análises, 18,9\% das cooperativas apresentaram como predominante a cultura de mercado, também denominada de cultura racional. Não associado aos aspectos tradicionais de mercado consumidor, o modelo aborda uma organização com um tipo de mercado próprio, ou seja, voltado às influências externas relacionadas às suas atividades específicas. Para a obtenção da eficácia, são tomados como base os resultados, os clientes e demais fatores externos que contribuem para o desenvolvimento organizacional. Nesse modelo, a cultura é focada à competitividade e à produtividade como elementos de influência da organização, ou seja, as metas voltadas aos resultados e devem ser sempre buscadas e alcançadas pelos membros que compõem tal gestão.

Por fim, 32,5\% das cooperativas foram tipificadas com a cultura organizacional hierárquica. Para Cameron e Quinn (2006), o modelo de cultura hierárquica é caracterizado pelos fatores motivacionais, burocráticos e conservadores no comportamento das organizações. A cultura organizacional compatível a essa forma de gestão é caracterizada por um local formalizado e estruturado para se trabalhar, no qual as regras formais e políticas internas mantêm a organização em continuidade.

A última análise a ser desenvolvida refere-se a uma proposta de agrupamento das 37 cooperativas. Conforme descrito nos aspectos metodológicos da pesquisa, a proposta de agrupamentos das unidades cooperativas, investigadas, tem por objetivo verificar se há 
características de práticas de contabilidade gerencial e de cultura organizacional comuns entre elas a partir da visão dos contadores. Essa ideia teve como suporte ferramental a utilização do software NVIVO ${ }^{\circledR}$ versão 11 , cujos procedimentos viabilizaram a identificação ou não de clusters específicos.

O processo de agrupamentos dividiu-se basicamente em cinco etapas. A primeira delas consistiu na tabulação dos dados coletados, de modo que, para a análise foram relacionadas as características das seis dimensões propostas pelo CVM de Cameron e Quinn (2006) e as práticas de contabilidade gerencial identificadas estabelecidas no modelo do IFAC (1998). A segunda etapa foi a inserção dessas observações por organização cooperativa analisada, por meio da exportação desses dados externos junto ao programa. Dessa forma, a terceira etapa se constituiu na exploração dos dados via Análise de Clusters. Para esse fim, o NVIVO® solicitou as fontes de pesquisa, que foram os dados cooperativa a cooperativa, onde os clusters foram analisados por similaridade de palavras. Em linhas gerais, o software buscou nos respectivos dados estruturados para cada cooperativa investigada, a similaridade de respostas às seis dimensões relacionadas às características culturais e às práticas de contabilidade gerencial. Para avaliação das similaridades de palavras, o NVIVO ${ }^{\circledR}$ atribuiu o coeficiente de correlação de Pearson que estabelece um índice de similaridade que varia entre -1 (menos similar) e 1 (mais similar), o qual foi utilizado nas análises (Hair Jr. et al., 2005).

$\mathrm{Na}$ quarta etapa, o modelo foi propriamente rodado, gerando um dendograma para a análise dos respectivos agrupamentos identificados. O dendograma refere-se à representação gráfica dos clusters. Para Hair Jr. et al. (2005, p.382), é uma "representação gráfica (gráfico em árvore) dos resultados de um procedimento hierárquico no qual cada objeto é colocado em um eixo e o outro eixo representa os passos no procedimento hierárquico." Hair Jr. et al. (2005, p.383) definem ainda objeto como "pessoa, produto ou serviço, empresa ou qualquer outra entidade que possa ser avaliada quanto a uma determinada quantidade de atributos." A quinta e última etapa se refere especificamente à interpretação do dendograma e dos respectivos clusters formados entre as unidades cooperativas. Após relacionadas todas as características necessárias para a construção dos possíveis agrupamentos, chegou-se ao dendograma demonstrado na Figura 2.

Figura 2 - Dendograma dos clusters

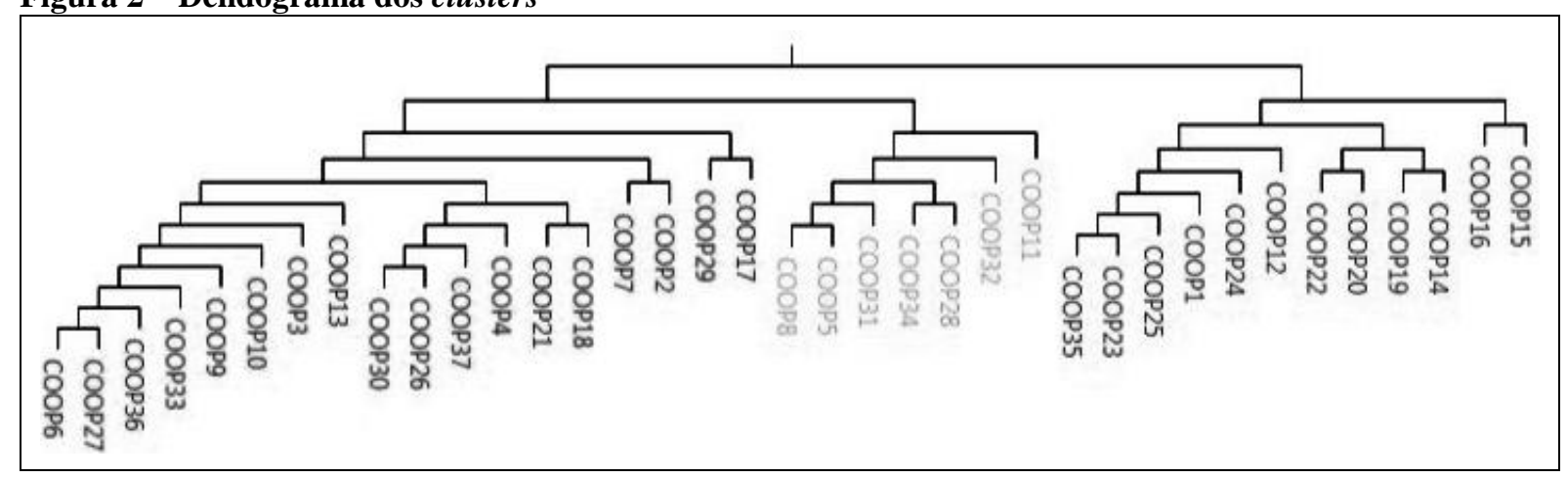

Fonte: dados da pesquisa.

Com base no dendograma gerado pelo NVIVO®, a partir das práticas de contabilidade gerencial e das características de cultura organizacional das cooperativas paranaenses, foi possível identificar três clusters principais, bem como demais subagrupamentos. Cabe ressaltar que não foi realizada análise de cluster a partir de dados quantitativos, tendo em vista as variáveis de cultura organizacional possuírem natureza qualitativa. Por esse fim, a partir do agrupamento de palavras relacionadas às variáveis de cultura organizacional e práticas de contabilidade gerencial foi possível identificar os três clusters principais. 

COOPERATIVO

Nesse sentido, pode-se demonstrar as características entre as práticas de contabilidade gerencial e as tipologias de cultura organizacional predominantes, conforme apontado da questão de pesquisa. O cluster 1 foi formado pelas cooperativas 1, 12, 14, 15, 16, 19, 20, 22, $23,24,25$ e 35 cuja tipologia cultural predominante observada foi a hierárquica. Destaca-se ainda que, dentro de cada cluster criado, algumas cooperativas se aproximaram mais, como por exemplo, as cooperativas 15 e 16 do dendograma. Tal fato pode ser explicado pela proximidade, além da cultura organizacional, de características semelhantes de práticas de contabilidade gerencial. Logo, a proposição $\mathbf{P 2}$ estabelecida no estudo foi aceita. O cluster 2 foi formado pelas cooperativas $5,8,11,28,31,32$ e 34 , cuja predominância cultural foi a de mercado, também aceitando a proposição P4. Por fim, o cluster 3 contemplou a maior quantidade de organizações, formado pelas cooperativas 2 , 3, 4, 6, 7, 9, 10, 13, 17, 18, 21, 26, 27, 29, 30, 33, 36 e 37, com a tipificação cultural grupal também aceitando a proposição P1. Como não houve classificação na tipologia cultural inovativa, conforme apresentado na seção 4.2 , a proposição $\mathbf{P 3}$ foi refutada.

Figura 3 - Tagclouds dos agrupamentos

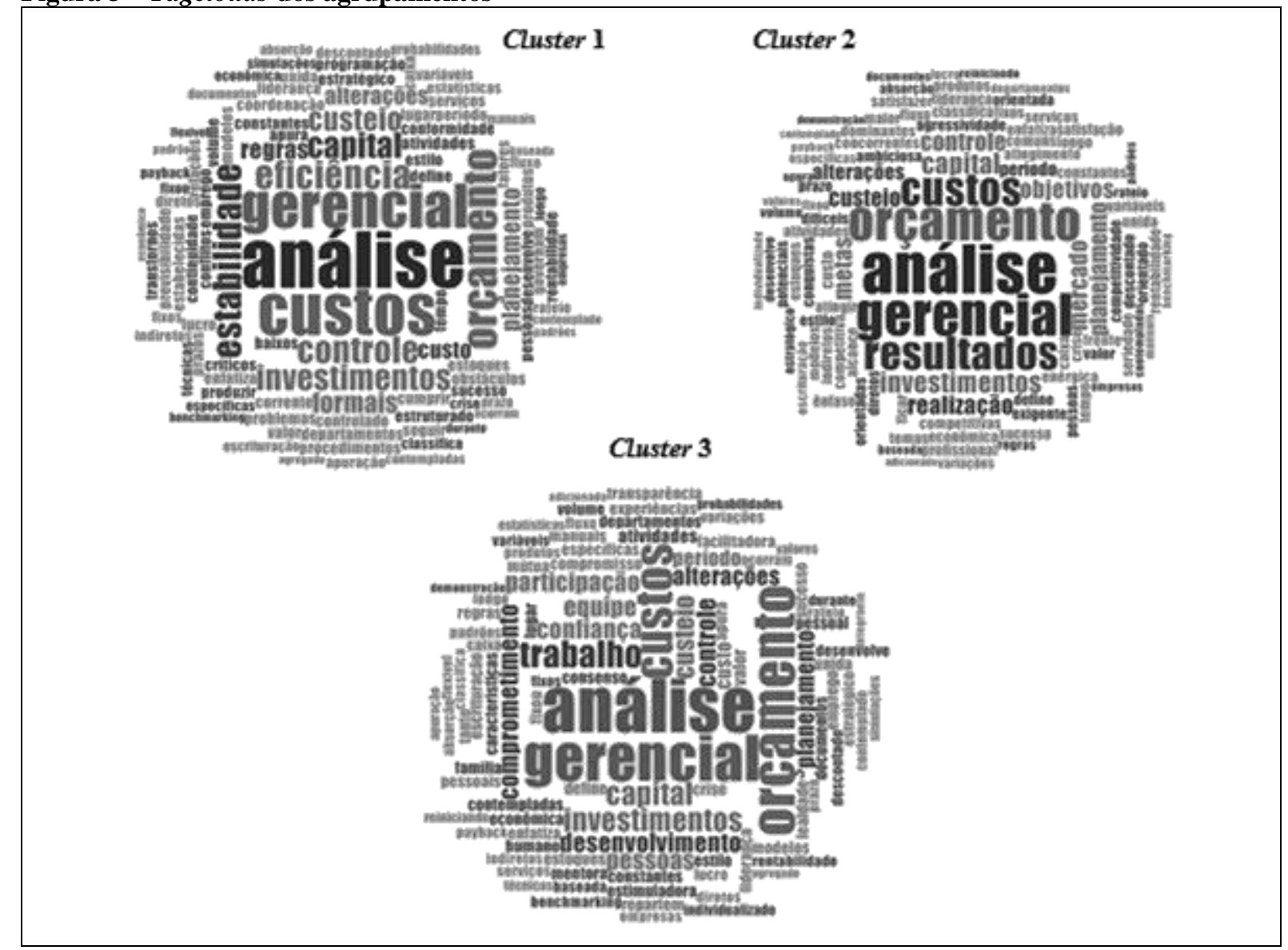

Fonte: dados da pesquisa.

A Figura 3 demonstra as tagclouds criadas a partir dos 3 clusters identificados nas análises. Nas respectivas tagclouds podem ser observadas as palavras mais frequentes relacionadas às variáveis de cultura organizacional e práticas de contabilidade gerencial. No cluster 1, onde a cultura organizacional predominante foi a hierárquica, ou seja, caracterizada pelos fatores motivacionais, burocráticos e conservadores no comportamento das cooperativas, pode-se observar que os níveis de utilização de ferramentas de contabilidade gerencial concentraram-se nos Estágios 1 e 2, corroborando parcialmente a pesquisa de Isidoro et. al. (2012) que demonstrou tais estágios de artefatos gerenciais em cooperativas. Já o cluster 2 , 
onde a cultura predominante foi a de mercado, refletida nas influências externas relacionadas às atividades específicas das cooperativas, a ênfase de nível de ferramentas gerenciais se deu no Estágio 2. Por fim, as cooperativas agrupadas no cluster 3, cuja predominância cultural foi a grupal, refletindo a aspectos de similaridade às organizações familiares, os 4 Estágios de utilização de ferramentais de contabilidade gerencial foram identificados.

Analisar a relação entre algumas das variáveis contempladas pela pesquisa torna-se sugestão para futuros estudos, em virtude do objetivo geral da pesquisa ser o de investigar se as cooperativas agropecuárias paranaenses com tipificações de cultura organizacional predominantes tendem a utilizar níveis de práticas de contabilidade gerencial.

\section{CONCLUSÕES}

As pesquisas que utilizam o método survey geralmente demonstram resultados relevantes e que geram variáveis específicas para estudos posteriores. Não cabe ao presente estudo a generalização dos achados a todo setor cooperativista de agronegócio brasileiro, porém, em virtude da diversificação de características da amostra investigada, os resultados podem representar aspectos interessantes da atividade. Para uma reflexão final, cabe trazer novamente a questão norteadora do estudo: quais as relações entre as tipificações de cultura organizacional clã/grupal, inovativa, mercado/racional e hierárquica predominantes e os níveis de práticas de contabilidade gerencial das cooperativas agropecuárias paranaenses? Em linhas gerais, os objetivos foram prontamente atingidos conforme os dados levantados pela amostra e posteriormente analisados.

No contexto das práticas de contabilidade gerencial, a pesquisa demonstrou resultados muito próximos a estudos anteriores já apontados. Ainda há um paradoxo entre teoria e prática na contabilidade gerencial. Ou seja, apesar dos mais diversificados ferramentais de contabilidade gerencial contemplados pela literatura da área, ainda são utilizadas de maneira incisiva as ferramentas mais tradicionais. Em relação aos estágios evolutivos, as práticas estão contempladas nos quatro estágios, porém com ênfase nos iniciais. A partir disso é possível verificar uma real necessidade de disseminação dos benefícios da utilização de práticas contábeis gerenciais mais diversificadas, a fim de se estabelecerem informações cada vez mais confiáveis para um cenário de ampla competitividade internacional.

Um dos fatores que pode explicar esse paradoxo foi diretamente relacionado na pesquisa: a cultura organizacional predominante. Como as culturas se moldam nas organizações ao longo do tempo, aspectos como coletividade, influências de fatores exógenos e práticas voltadas a aspectos mais burocráticos refletem nas práticas gerenciais das entidades. Além de aspectos como as características dominantes, de liderança, de gerenciamento de pessoas e equipes, de união organizacional, de estratégia e de sucesso.

O estudo mostrou ainda que a contabilidade gerencial não deve ser analisada de forma isolada, ou seja, os fatores internos organizacionais e externos de cenários econômicos, políticos e sociais podem moldar as práticas. Fatores institucionais como a criação de legislações específicas para a atividade cooperativista (Lei 12.973/2014), o ICPC 14 (SANTOS; LONDERO, 2017), além da crise política e econômica presente no Brasil, são fatores capazes de alterar as práticas de contabilidade gerencial, refletindo através do tempo no perfil de cultura organizacional das cooperativas.

Cooperativas caracterizadas com cultura hierárquica, mais conservadoras e tradicionalistas tendem a utilizar ferramentas de contabilidade gerencial mais tradicionais e intermediárias, estabelecidas nos estágios 1, 2 e 3 do IFAC (1998). Já as cooperativas cuja cultura predominante foi a de mercado, tendem a utilizar ferramentas intermediárias, estabelecidas nos estágios 2 e 3 do IFAC (1998). Por fim, conforme as análises da pesquisa, cooperativas com cultura grupal cuja gestão é muito semelhante aos aspectos familiares, tendem a utilizar ferramentas gerenciais diversificadas nos estágios evolutivos $1,2,3$ e 4 do IFAC 
(1998). Abdel-Kader e Luther (2008) identificaram comportamentos similares específicos apenas às características das práticas de contabilidade gerencial.

Como forma de ampliar esse estudo, motiva-se a investigação de outros aspectos além da cultura organizacional como fatores que influenciam ou são influenciados pelas práticas de contabilidade gerencial. As próprias variáveis utilizadas no estudo são passíveis de relação com outros aspectos. O relacionamento de teorias organizacionais e econômicas ainda é um amplo campo a ser explorado como forma de minimizar as proposições contempladas nas literaturas e a realidade encontrada nas empresas.

\section{REFERÊNCIAS}

ABDEL-KADER, M; LUTHER, R. G. IFAC's conception of the evolution of management accounting. Advances in Management Accounting, v. 15, p. 237-256, 2006.

ABDEL-KADER, M; LUTHER, R. G. The impact of firm characteristics on management accounting practices: a UK-based empirical analysis. British Accounting Review, v. 40, n.1, p. 2-27, 2008.

AHRENS, T.; KHALIFA, R.; BECKER, A.; HABERSAM, M.; PIBER, M.; SCHEYTT, T.; BURNS, J.; CHAPMAN, C. S.; QUATTRONE, P.; GRANLUND, M.; HANSEN, A.; MALMI, T.; MENNICKEN, A.; MIKES, A.; PANOZZO, F. The future of interpretive accounting research: a polyphonic debate. Critical Perspectives on Accounting, v. 19, n.6, p. 840-866, 2008.

AHRENS, T.; MOLLONA, M. Organisational control as cultural practice: a shop floor ethnography of a Sheffield steel mill. Accounting. Organizations and Society, v.32, p. 305331, 2007.

ALTMAN, M. Cooperative organizations as an engine of equitable rural economic development. Journal of Co-operative Organization and Management, ICA Global Research Conference, v.3, n.1, p. 14-23, 2015.

ANTHONY, R. N.; GOVINDARAJAN, V. Management Control Systems. New York: Irwin-McGraw-Hill, 1998.

AX, C.; GREVE, J. Adoption of management accounting innovations: Organizational culture compatibility and perceived outcomes. Management Accounting Research, p. 1-16, 2016.

BIALOSKORSKI NETO, S.; BARROSO, M. F. G.; REZENDE A. J. Co-operative governance and management control systems: an agency costs theoretical approach. Brazilian Business Review, v.9, n.2, p.72-92, 2012.

BRASIL. MAPA - Ministério da Agricultura, Pecuária e Abastecimento. Estatísticas. Disponível em http://www.agricultura.gov.br/vegetal/estatisticas. Acesso em: 30 nov. 2016.

BROMWICH, M.; SCAPENS, R. W. Management Accounting Research: 25 Years On. Management Accounting Research, v. 31, p. 1-11, 2016.

BURNS, J.; SCAPENS, R. W. Conceptualizing management accounting change: an institutional framework. Management Accounting Research, v.11, p. 3-250, 2000. 
BUSCO, C.; SCAPENS, R. W. Management accounting systems and organizational culture: interpreting their linkages and processes of change. Qualitative Research in Accounting \& Management, v.8, n.4, p. 320-357, 2011.

CAMERON, K. S.; QUINN, R. E. Diagnosing and changing organizational culture: based on the competing values framework. Revised edition. San Francisco: Jossey-Bass, 2006.

CHOW, C. W.; HARRISON, G. L.; MCKINNON, J. L.; WU, A. The organizational culture of public accounting firms: evidence from Taiwanese local and US affiliated firms.

Accounting, Organizations and Society, v.27, p. 347-360, 2002.

CHOW, C. W.; SHIELDS, M. D.; WU, A. The importance of national culture in the design of and preference for management controls for multi-national operations. Accounting, Organizations and Society, v.24, n.5, p. 441-461, 1999.

COOK, M. L.; CHADDAD, F. R.; ILIOPOULUS, C. Advances in cooperative theory since 1990: a review of agricultural economics literature. In: HENDRIKSE, G. W. J.

Restructuring agricultural cooperatives. Rotterdam: Erasmus University Rotterdam, 2004. pp. 65-90.

COOPER, C. Entrepreneurs of the self: the development of management control since 1976. Accounting, Organizations and Society, v.47, p. 14-24, 2015.

DENT, J. F. Accounting and organizational cultures: a field study of the emergence of a new organizational reality. Accounting, Organizations and Society, v.16, p. 705-732, 1991.

DOS REIS, Antonio Marcos; TEIXEIRA, Aridelmo José Campanharo. Utilização de artefatos de contabilidade gerencial nas sociedades cooperativas agropecuárias de Minas Gerais e sua relação com porte e desempenho financeiro. Revista de Educação e Pesquisa em Contabilidade (REPeC), v. 7, n. 4, 2013.

GEERTZ, C. The interpretation of cultures. New York: Basic Books, 1973.

GRANDE, J. F.; BEUREN, I. M. Mudanças de práticas de contabilidade gerencial: aplicação da análise de discurso crítica no relatório da administração de empresa familiar. Revista Base (Administração e Contabilidade) da UNISINOS, v. 8, n. 2, 2011.

GUERREIRO, R.; CORNACHIONE JR., E. B.; SOUTES, O. D. Empresas que se destacam pela qualidade das informações a seus usuários externos também se destacam pela utilização de artefatos modernos de contabilidade gerencial? Revista Contabilidade \& Finanças, v.22, n.55, p.88-113, 2011.

HAIR Jr., J. F.; ANDERSON, R. E.; TATHAM, R. L.; BLACK, W. C. Análise Multivariada de Dados. 5. ed. Porto Alegre: Bookman, 2005.

HENRI, J. F. Organizational culture and performance measurement systems. Accounting, Organizations and Society, v.31, p. 77-103, 2006.

HOFSTEDE, G. Culture's consequences: international differences in work related values. Beverly Hills: Sage Publications, 1985. 
HOFSTEDE, G. What is culture? A reply to Baskerville. Accounting, Organizations and Society, 28. pp. 811-813, 2003.

ICA - International Co-operative Alliance. What is a co-operative? 2008. Disponível em: http://www.ica.coop/coop/index. Acesso em: 30 nov. 2016.

IFAC - International Federation of Accountants (1998). Management Accounting Concepts: revised reports. p.82-100.

ISIDORO, C.; FACCI, N.; ESPEJO, M. M. S.; GARCIAS, P. M. A utilização de artefatos de contabilidade gerencial em cooperativas agropecuárias. Revista de Contabilidade da Universidade Federal da Bahia. UFBA, v.6, n.2, p.39-55, 2012.

JOHNSON, H. T.; KAPLAN, R. S. Managerial accounting: the restoration of the relevance of accounting in business. Rio de Janeiro: Campus, 1993.

MALMI, T. Reflections on paradigms in action in accounting research. Management Accounting Research, v.21, n.2, p. 121-123, 2010.

MINKOV, M.; HOFSTEDE, G. Hofstede's fifth dimension: new evidence from the World Values Survey. Journal of Cross-Cultural Psychology, v.43, n.1, p. 3-14, 2012.

OCB - Organização das Cooperativas Brasileiras. Relatório de atividades. Disponível em http:Iwww.ocb.org.br. Acesso em: 25 out. 2016.

SANTOS, A. dos; LONDERO, P. R. ICPC 14: o que está faltando? Revista Contabilidade \& Finanças. USP, v.28, n.75, p. 478-485, 2017.

SCHEIN, E. H. Organizational culture and leadership. 2. ed. San Francisco: Jossey-Bass, 1992.

SOETERS, J.; SCHREUDER, H. The interaction between national and organizational cultures in accounting firms. Accounting, Organizations and Society, v.13, p. 75-86, 1988.

TEIXEIRA, A. J. C.; GONZAGA, R. P.; MOREIRA SANTOS, A. V. S.; NOSSA, V. A utilização de ferramentas de contabilidade gerencial nas empresas do Estado do Espírito Santo. BBR-Brazilian Business Review, v. 8, n. 3, 2011.

VAN DER STEDE, W. A. The effect of national culture on management control and incentive system design in multi-business firms: evidence of intracorporate isomorphism.

European Accounting Review, v.12, n.2, p. 263-285, 2003.

VIEIRA FILHO, J. E. R. Transformação histórica e padrões tecnológicos da agricultura brasileira. In: BUAINAIN, A. M,; ALVES, E.; SILVEIRA, J.M.; NAVARRO Z. O mundo rural no Brasil do século 21: a formação de um novo padrão agrário e agrícola. Brasília-DF: Embrapa, 2014. pp. 395-422. 